\title{
AC 2007-1865: INTERNATIONAL TECHNICAL SERVICE IMMERSIONS: MODEL FOR DEVELOPING GLOBAL SCIENTISTS AND ENGINEERS IN SMALL TO MID-SIZE UNIVERSITIES
}

Margaret Pinnell, University of Dayton

Vipul Ranatunga, Miami University-Ohio

Eger Bill, University of Dayton

Phillip Aaron, University of Dayton

Charles Schreier, University of Dayton 


\section{International Technical Service Immersions: Model for Developing Global Scientists and Engineers in Small to Mid-Size Universities}

\section{Abstract:}

The University of Dayton (UD) Engineers in Technical Humanitarian Opportunities of Service-learning (ETHOS) program is working to further develop the international technical immersion program such that it can serve as a model that can be easily adopted by peer institutions (small to mid-size colleges and universities). The ETHOS immersions are ten to sixteen weeks long, during which students work with collaborating organizations to assist in finding appropriate, and effective solutions to technical challenges. Students use their engineering skills to address real problems, while gaining a better understanding of the interface between technology and global society. Academic credit is incorporated into these immersions with technical reporting, reflections and presentations delivered upon completion of the program. Pre-immersion course work includes research and engineering fundamentals, cultural immersion, language development, and ethical engineering practices. Feedback provided by students, collaborating agencies and other institutions have indicated that the current program does a very good job of preparing the students for their immersions and helping the students to become global engineers. Although there are many well established international technical opportunities and programs that can be easily adopted by universities, it is often difficult, due to a lack of resources, to establish these programs at smaller universities. This paper will describe the ETHOS program and discuss the mechanics and resources used to facilitate this program. Additionally, this paper will discuss plans for intercollegiate collaboration through this program which will facilitate the sharing of information and resources

Background:

The turn of the century brought with it a paradigm shift in engineering education. The commonly employed lecture based pedagogy of the $20^{\text {th }}$ century is being replaced by various experiential teaching strategies. Part of the motivation for this change in pedagogy is in response to the changing needs of today's students. Many of the engineering students today have very little hands-on engineering experience and have been trained to learn differently as a result of multi media and other technology. Another motivator for the change in pedagogy is associated with a change in the engineering profession. Engineers today need not only be technically sound, but also have good communication, leadership and business skills. Furthermore, globalization in industry makes international experience an important, but often difficult to implement part of the engineering curriculum. 1,2

Experiential learning can be implemented into the engineering curriculum in a variety of ways including co-ops, internships, project and problem based learning, laboratory experiences and service-learning. However, integration of international experience into an already packed engineering curriculum can be a little more difficult to attain. Study abroad, international internships and co-ops and international service-learning represent some of the ways in which engineering academia has provided international experiences for some of its students. Although all of these international experiences have been found to be beneficial in better preparing students for the global market place, students participating in international service-learning not 
only get the benefits associated from international experience, but also the benefits associated from participating in service-learning. ${ }^{1-10}$

Service-learning is the integration of service projects into the engineering curriculum that help to develop fundamental engineering skills through experiential learning while meeting the needs of a service-organization or a particular community. Service-learning has three basic components: "course" structure, community service and structured reflection. Many papers have been written that summarize the benefits of service-learning in engineering . ${ }^{4,5,8,11-18}$ Some of the key benefits that have been identified in these papers include helping students to develop technical and non-technical skills, enhancing the students' problem solving skills, creativity and ability to adapt to difficult situations, helping students to make connections between classes and to develop racial and cultural sensitivity, enhancing the students' commitment to civic responsibility and increasing their ethical awareness and awareness of the impact of professional decisions on society and the environment. When service-learning is combined with international experience, students are able to develop fundamental engineering skills, foreign language skills, an increased cultural awareness and a global sense of civic responsibility. Furthermore, international service-learning experiences have changed the participants' understanding of the philosophy of engineers in society and in the world.

Many universities have realized the benefit of international service-learning in engineering. A variety of different approaches have been employed to facilitate these experiences. The Engineers for Community Service (ECoS) program at The Ohio State University includes both local service-learning opportunities as well as international servicelearning in a variety of countries. ${ }^{22}$ Marquette University's College of Engineering offers the Health, Environment and Infrastructure in Latin America (HEILA) course where engineering students learn about the history, culture, and politics of Latin America, explore the importance of their major as related to international development, and then participate in a twelve day service trip to a country in Latin America or engage in a service project in the Latino community of Milwaukee . ${ }^{23}$ The School of Engineering at the University of Massachusetts Lowell offers the Service Learning Integrated College of Engineering Program (SLICE) that includes both local and international service-learning projects. The international service-learning projects facilitated through the SLICE program are fully integrated into existing courses in a variety of engineering and non-engineering courses available for students at all stages of their academic career. ${ }^{24}$ The Picker Engineering Program at Smith College recently started offering a course entitled Engineering and Global Development which integrates engineering fundamentals and liberal arts with international service. ${ }^{4}$ There are a variety of other international technical service programs and courses that exist at many universities. One of the most widely known programs that provides international service-learning opportunities to engineering students and service opportunities for engineering professionals is Engineers Without Borders (EWB). This program which was started in 2001 at Colorado University Boulder has realized explosive growth over the past six years. EWB has student and professional chapters at numerous universities and in many communities both in the United States and World Wide ${ }^{25}$ All of the aforementioned programs are well established and varied and beneficial experiences to engineering students.

At the University of Dayton (UD), international engineering service-learning is provided through the student developed Engineers in Technical Humanitarian Opportunities for Service- 
Learning (ETHOS) . this program was developed within the identity of Catholic Marianist University and was built upon the core principles of the Marianist educational philosophy which includes educating for formation in faith; providing an integral, quality education; educating in the family spirit; educating for service, justice, and peace and educating for adaptation and change. As such, it offers another unique opportunity for undergraduate students which could likely be reproduced at other similarly sized universities.

The ETHOS program at The University of Dayton:

The University of Dayton (UD) is a Roman Catholic University founded in 1850 by the Society of Mary (Marianists) . The University of Dayton is committed to educating the whole person and providing a transformative educational experience to its students. It has an undergraduate enrollment of approximately 7,000 undergraduate students and is ranked as one of the ten best Catholic universities in the United States. In alignment with its Marianist heritage, UD is committed to service and social justice and to fostering leadership in its students through service. The UD School of Engineering (UD SoE) offers six ABET-accredited undergraduate programs including Mechanical and Aerospace, Civil and Environmental, Electrical, Computer, Chemical and Technology . ${ }^{26}$ Although service-learning is incorporated into numerous engineering courses, further international service-learning opportunities are made available to engineering students and students from related disciplines (geology, physics, etc.) through the ETHOS Program.

The ETHOS program was developed in the spring of 2001 by an interdisciplinary group of undergraduate engineering students as a UD SoE sponsored capstone design project. Many of the students on the team that designed the ETHOS program had participated in international service through UD's Center for Social Concern. Although these experiences were very rewarding, the service projects the students participated in did not directly make use of their engineering skills. Furthermore, while participating in these service projects, the students identified many needs that could be addressed through engineering solutions. The students spent two semesters researching and designing the program, making initial contacts with potential placement partners and assessing the feasibility of the program from a university administration perspective. Today the program remains a student led effort with support and assistance from various faculty members and the SoE service-learning director. The program continues to grow in scope and in size, but the structure of the program and mission established by the founding students remains constant.

The ETHOS program was founded on the belief that engineers are better prepared to serve the world more appropriately if they have experienced opportunities that increase their understanding of technology's global linkage with values, culture, society, politics, and the economy. The ETHOS program seeks to provide these opportunities through international technical service-learning immersions, on-campus student organization activities, collaborative research and hands-on classroom projects that support the development and facilitation of appropriate and sustainable technologies for the developing world. Service-learning and appropriate technology serve as the core of the ETHOS program. Students that participate in the ETHOS program engage in research, testing and development activities associated with alternative and non-traditional technologies that are based on fundamental engineering principles 
and provide culturally appropriate solutions to problems. The technologies are developed to be environmentally sustainable, and made and maintained by the local people to promote self reliance and economic independence. ${ }^{27,28}$ The experiences provided through the ETHOS program allow students to recognize the far-reaching effects, positive and negative, of engineering and technology and the responsibility that an engineer is faced with in an everincreasing global society.

As previously mentioned, the ETHOS program reaches students in three primary ways: classroom projects, on-campus student organization and international technical service placements. To date most of the projects that have been incorporated into the classroom have focused on the design and testing of insulative brick materials used in biomass cookstoves, thermal analysis of these materials and testing and failure analysis of metals used in biomass cookstoves. This analysis has always been conducted in affiliation with other non-university partners in order to incorporate the greater mission of global promotion of appropriate technology. Furthermore, the ETHOS classroom projects have given students the opportunity to practice program management, communication skills and problem solving while allowing them to reflect upon some of the social, ethical, and humanitarian issues associated with engineering. ${ }^{29}$ Although most of the classroom projects have been implemented in mechanical engineering courses and have focused on biomass stove development, as the interest and scope of the ETHOS program increases and partnerships continue to develop, other projects are being identified and proposed for integration into the classroom. Furthermore, several students have identified ETHOS related research projects for their undergraduate research topic.

Another way in which the ETHOS program reaches students is through an on-campus student organization. The ETHOS club seeks to provide local and domestic technical servicelearning opportunities for students and to promote awareness of global technical issues and their effects on society. The ETHOS club facilitates various activities such as club meetings, oncampus appropriate technology demonstrations, a guest lecture series, field trips, collaboration with community organizations, and local, district and state junior and senior high school science fair award sponsorship. The ETHOS club strives to attract first year students as many of the other aspects of the ETHOS program are not available until after the sophomore year. The major operation of the Club is to support projects occurring on campus and to raise awareness about the ETHOS program and its mission to the entire UD student body..

Of the various educational opportunities offered by the ETHOS program, the international technical service-learning immersions are believed to have the biggest impact on the attitudes and perceptions of the students. Many students describe their ETHOS technical service-learning internship as "life changing." Since its inception in 2001, ETHOS has sent more than 40 engineering students to developing countries to participate in technical immersions with development organizations and communities. Some of the countries where the students have worked include Nicaragua, Honduras, Brazil, Mexico, Bolivia, Cameroon and Peru. Through these technical immersions, students have been involved with projects related to biomass stove design, solar cooker design and production, photovoltaic system design and construction, refractory brick design and well-field analysis and design . In the summer of 2007, the ETHOS program will send 23 students on technical service-learning immersions. 
ETHOS International technical service-learning immersions:

The ETHOS international technical immersions are offered as part of a three semester hour course, Engineering Design and Appropriate Technology. This course spans three semesters. During the winter semester, students meet once a week for two hours and participate in additional hands-on activities, fund raisers and preparatory exercises. The meetings are facilitated by the ETHOS administration, engineering faculty, Spanish Department faculty, and UD's Center for Social Concern staff. The winter semester meetings are broken into three distinct components: language preparation, cultural immersion and technical preparation.

In the sixteen week semester, students participate in a language preparation "crash" course for four of the meetings. Although this crash course is notably insufficient in preparing the students for their travels, it does serve as a motivator for self-study and exposes them to the resources available on campus such as the language lab. The crash course is supplemented by foreign language movie nights where the students get together to watch a popular movie in Spanish or another language.

For six of the sixteen meetings, the ETHOS students join with other students from all different majors who are participating in immersion trips in a cultural immersion course. This course is facilitated through the Center for Social Concern and has been highly rated by the ETHOS students. The cultural immersion course covers very important and practical information associated with international travel such as cultural sensitivity, passports, vaccinations and health issues, packing tips, travel safety and the personal formation associated with travel.

The remaining six meetings are reserved for organizational meetings, placement information, fund raising, an introduction to appropriate technology and hands-on technical training. The students are also required to participate in additional appropriate technology hands-on activities and demonstrations that are facilitated outside of the normal meeting time as well as organize and participate in group fund-raisers. Examples of some of these fund raisers include university facility clean-up, corn hole or other tournaments and donut sales. Throughout the semester, students are assigned various readings and reflections on both technical and nontechnical topics and are required to conduct independent research that helps them to better prepare for their immersions.

During the summer semester, the ETHOS students participate in the international technical service-learning immersions. Students travel in small teams of two to three students each and live individually with host families that the partner organization arranges. The students must stay at their placement for a minimum of eight weeks. Although there is no maximum amount of time the students can stay, they typically do not stay more than sixteen weeks. During the technical service-learning immersions the students work with collaborating organizations and communities to assist in finding appropriate, sustainable and effective solutions to technical challenges through guided research, development projects, and technology dissemination. Students use their engineering knowledge to address real world problems, while gaining a better understanding of the interface between technology and global society. While traveling, students are required to provide weekly electronic status reports to the ETHOS administration. Due to the 
nature of their living arrangements they are forced to engage in local culture including language, infrastructure, and general lifestyle.

During the fall semester, students return to campus write a technical report summarizing their work, write a reflection report, attend a dissemination dinner, submit an expense report and give two presentations. At least one of these presentations has to be on campus, but the students are encouraged to give the second presentation off campus. Examples of some of the offsite presentations include a local middle school, a local high school, Lion's Club and a variety of local and national professional conferences.

Grades are given to the students enrolled in the Engineering Design and Appropriate Technology in accordance with Table 1, provided below.

Table 1: EGR330 Grading for the Engineering Design and Appropriate Technology Course

\begin{tabular}{|l|l|}
\hline Item & Weight (\%) \\
\hline Class attendance & $\mathbf{1 0}$ \\
\hline Homework & $\mathbf{1 0}$ \\
\hline Weekly Status Reports $(6-12)$ & $\mathbf{1 0}$ \\
\hline Reflection Paper & $\mathbf{2 0}$ \\
\hline Technical Report & $\mathbf{3 0}$ \\
\hline Expense Report & $\mathbf{1 0}$ \\
\hline Presentations (at least two) & $\mathbf{1 0}$ \\
\hline Total & $\mathbf{1 0 0}$ \\
\hline
\end{tabular}

The Engineering Design and Appropriate Technology course is offered to undergraduate engineering (or related discipline) students who have completed their sophomore year. Graduating seniors are also eligible to take this course as an assigned readings course, but must complete the technical report and presentation requirements prior to graduation. Graduating students complete the technical report requirements by writing an in depth research paper. Students are encouraged to go on more than one technical immersion trip, but can not receive additional credit for doing this unless they undertake a more in depth project that serves as that student's undergraduate thesis. The technical immersions are also available to graduate students, but no academic credit is offered for their participation.

Support of the ETHOS International Technical Service-learning Immersions

The ETHOS program receives financial and non-financial support from a variety of sources. The average cost to send a student on a technical immersion is $\$ 2,000$. Additional costs such as supplies, educational materials, administrative costs, mailings, the dissemination dinner and other activities are also incurred to support this program. Although the students are not expected to pay anything to participate in these immersions, each student is expected to raise $\$ 700$ through family letters and by participating in group fund raisers. Additional financial support for their travels is provided by the Center for Social Concern, UD SoE, private and corporate donations. 
The Center for International Programs (CIP) at UD provides support to the ETHOS students in the form of passport seminars, travel information and assistance. Additionally, the CIP oversees all student travel, keep a data base of traveling students and facilitate an emergency response team. The travel agency on campus provides assistance to the students in arranging flights and other travel details. ETHOS participants receive technical support from UD and University of Dayton Research Institute (UDRI) faculty and staff in preparation for and during their technical immersions. Support for language preparation is provided through the Language Department's Language Lab. The campus health center provides assistance with vaccinations and other health related issues.

Summary of Program Assets:

There are an increasing number of programs offered by Universities and organizations that facilitate international service-learning experiences for engineering students. Like many of these programs, ETHOS has many assets that facilitate the development of practical reasoning, interpersonal communication, research and development skills and technical knowledge in an international context. These experiences aid in the development of individuals whose balanced abilities are optimal for successful leadership in a global market. Some of the key assets of the ETHOS program are:

- Students participate in well established cultural immersion, language and technical preparation of students;

- The program has many well established partnerships with organizations that are provide meaningful research projects and on-site mentorship for students in all engineering disciplines;

- Student travel costs are paid for through fundraising, donations and support from the university.

- Integrated class-room projects provide the participating students with the opportunity to continue their research and engage other students in their research upon their return

- The program was developed by students, for students;

- Students travel in small teams and live individually with host families which enhances their cultural immersion experience;

- Students travel for a minimum of eight weeks which assists them in becoming proficient in a foreign language and allows them to engage in "long" term appropriate technology research projects;

- Students are required to work on teams in fund raising and preparation class activities which is useful in establishing a strong sense of community among the participating students;

- The program receives significant support from individuals, companies and organizations as well as from a variety of on-campus resources including Center for Social Concern, CIP, UD and UDRI faculty and staff, former ETHOS participants and alumni, Health Center and SoE. 
- Course requirements such as the technical reports, presentations and dissemination dinner provides the students with the opportunity to share their experiences to a large and diverse audience

Future Plans:

The ETHOS program is currently working to establish relationships with other schools to facilitate intercollegiate technical service-learning immersions. In the near future (2008), The ETHOS administration, Center for Social Concern and partnering universities will work to expand the existing technical immersion preparatory course at UD to include a distance learning component. This will enable students from partnering institutions to make use of the well established course structure that exist for the Engineering Design and Appropriate Technology course at UD. In addition to the distance learning course, past UD ETHOS students will travel to the partnering institutions to discuss the program and to recruit students to participate in the technical service-learning immersions. During the winter semester, students from the partnering institution will travel to UD to participate in a weekend ETHOS workshop that will include a hands-on appropriate technology laboratory experience, community building activities, and fundraising events. In the summer semester, students will be placed on intercollegiate teams of two to three students to participate in international technical immersion experiences with one of the international partners. Faculty and ETHOS students from the partnering institution will be invited to attend the dissemination dinner held at UD. It is believed that this partnership will allow students from smaller universities that may not have the resources to facilitate such a program to participate in an international technical service-learning internship and also interact with students from another university.

\section{References}

[1] Scheibler, S. Creating a "Global Algorithm" for Engineering Education,, Proceedings of the 2006 ASEE Annual Conference and Exposition, ASEE, 2006.

[2] Wakeland, H. L. International Education for Engineers: A Working Model, ANNALS, AAPSS: 511, September 1990..

[3] Doerry, E., Doerry, K., Bero, B., Providing an Integrated International Experience for Undergraduate Engineering Students at a Small Institution, Proceedings of the 2006 ASEE Annual Conference and Exposition, ASEE, 2006.

[4] Riley, D., Bloomgarden, A.H., Learning and Service in Engineering and Global Development, International Journal for Service-Learning in Engineering, Vol 2, No 1, pp. 48-59, Fall 2006.

[5] Gordon, R., Gordon, A., Bedient, P., Rice University Engineers Without Borders: An Exercise in International Service Learning, Proceedings of the 2006 ASEE Annual Conference and Exposition, ASEE, 2006.

[6] Frank, M., Lavy, I., Elata, D., Implementing the Project-Based Learning Approach in an Academic Engineering Course, International Journal of Technology and Design Education, 13, pp. 373-288, 2003. 
[7] Pérez-Foguet, A, Oliete-Josa, S., Saz-Carranza, A.,Development education and engineering: A framework for incorporating reality of developing countries into engineering studies, International Journal of Sustainability in Higher Education, vol. 6, no. 3, pp. 278-303, 2005.

[8] Husfeld, R., Polito, C., Gingerich, E., Lessons Implemented on an International Service Learning Project, Proceedings of the 2006 ASEE Annual Conference and Exposition, ASEE, 2006.

[9] Mason, D.E., et. al., Innovation in a Large-Scale Study-Abroad Program in Engineering, Proceedings of the 2004 ASEE Annual Conference and Exposition, ASEE, 2004.

[10] Johnson, E., DeMaris, S., Tougaw, D., Providing an Integrated International Experience for Undergraduate Engineering Students at a Small Institution, Proceedings of the 2006 ASEE Annual Conference and Exposition, ASEE, 2006.

[11] Tsang, E., Projects that Matter: Concepts and Models for Service Learning in Engineering, AAHE, Washington D.C., (2000).

[12] Duffy, J. Service Learning in a Variety of Engineering Courses, Projects that Matter: Concepts and Models for Service Learning in Engineering, AAHE, E. Tsang, ed., Washington D.C., (2000).

[13] Morton, Keith, A Smart Start to Service-Learning, Journal of Business Ethics: 15, pp 21-32 (1996).

[14] Eyler, J., What I Never Learned in Class: Lessons from Community Based Learning, Projects that Matter: Concepts and Models for Service Learning in Engineering, AAHE, E. Tsang, ed., Washington D.C., (2000).

[15] Engineering Projects in Community Service," Purdue University, http://epics.ecn.purdue.edu/ Accessed January 12, 2007.

[16] Paterson, K., et.al., International Service Engineering Across Academic Borders, Proceedings of the 2006 ASEE Annual Conference and Exposition, ASEE, 2006.

[17] C. Eger, M. Pinnell, and C. Shreier, Engineers in Technical, Humanitarian Opportunities of Servicelearning Annual Report 2004-2005, The University of Dayton, 2005.

[18] Lucena, J., Downey, G.L., Engineering Cultures: Better Problem Solving through Human and Global Perspectives, Proceedings of the 1999 ASEE Annual Conference and Exposition, ASEE, 1999.

[19] Jamieson, L.H., Oakes, W.C., and Coyle, E.J., EPICS: Documenting Service-Learning to Meet EC 2000, Proceedings, ASEE/IEEE Frontiers in Education Conference, Session T2A, Reno, NV, October 10-13, 2001.

[20] Martin, P.T. and Coles, J., How to Institutionalize Service-Learning into the Curriculum of an Engineering Department: Designing a Workable Plan, Projects that Matter - Concepts and Models for ServiceLearning in Engineering, Tsang, E., Editor, A Publication of the American Association for Higher Education,, pp. 41-51, 2000.

[21] Kleinhenz, P, Pinnell, M, Mertz, G, Eger, C, Student Perspectives of Curriculum Integrated International Service-Learning Internships, Proceeding of the 35th ASEE/IEEE Frontiers in Education Conference, October 19-22, 2005.

[22] http://ecos.osu.edu/taxonomy/term/2 accessed 14 Jan 07

[23] http://www.marquette.edu/engineering/pages/AllYouNeed/international.htm accessed 14 Jan 07 
[24] http://www.slice.uml.edu/project_examples/1 accessed 14 Jan 07

[25] http://www.ewb-int.org accessed 14 Jan 07

[26] http://www.udayton.edu accessed 15 Jan 07

[27] Design Criteria for Sustainable Development in Appropriate Technology: Technology as if People Matter Robert C. Wicklein, ed. D. University of Georgia, USA

[28] Hazelton, B, Bull, C. Appropriate Technology: Tools, Choices and Implications, November 1988.

[29] Pinnell, M.F., Chuck, L., Developing Technical Competency and Enhancing the Soft Skills of Undergraduate Mechanical Engineering Students through Service-Learning, Proceedings of the 2004 ASEE Annual Conference and Exposition, ASEE, 2004. 